\title{
FutureJournal
}

\section{Fatores Motivadores de Empresas que Estabelecem Cooperação com Institutos de Ciência e Tecnologia}

\author{
Bruno Giovanni Mazzola \\ Doutorando em Administração pela Universidade de São Paulo (USP), Brasil \\ bruno.mazzola@usp.br \\ Augusto Takerissa Nishimura \\ Doutor em Administração pela Universidade de São Paulo (USP), Brasil \\ augusto.nishimura@usp.br

\section{Edson Carlos Germano} \\ Mestre em Administração pela Universidade de São Paulo (USP), Brasil \\ edson.germano@usp.br \\ Luiz Antonio Bloem da Silveira Junior \\ Doutorando em Administração pela Universidade de São Paulo (USP), Brasil \\ luizbloem@usp.br
}

\section{RESUMO}

A inovação tecnológica é considerada estratégica para que organizações e nações alcancem e sustentem a vantagem competitiva. Um dos meios mais efetivos para que as empresas obtenham essas inovações é por meio da relação com universidades. Nesse sentido, neste estudo o objetivo foi hierarquizar os principais fatores que motivam empresas a estabelecer esse tipo de parceria. Para tanto, foi realizado um estudo descritivo cujos respondentes são empresas que mantêm algum nível de cooperação com universidades e institutos de ciência e tecnologia. Os resultados demonstraram que os principais motivos são, por ordem de importância: (1) fortalecer a tecnologia; (2) buscar novas fontes de criatividade; (3) obter expertise em tecnologias para o mercado; (4) adquirir novas tecnologias; (5) acessar mão de obra qualificada; (6) capacitar seus recursos humanos; e (7) desenvolver novos produtos. Ademais, neste estudo verificou-se que o fator de menor importância está associado às razões sociais, que merecem ser mais bem investigadas em estudos futuros. 


\section{FutureJournal}

PALAVRAS-CHAVE: Cooperação universidade-empresa. Inovação tecnológica.

\section{Motivational Factors of Companies that Establish Cooperation with Institutes of Science and Technology}

\section{ABSTRACT}

Technological innovation is deemed strategic for organizations and nations to achieve and sustain competitive advantage. One of the most effective means for companies to achieve these innovations is through the relationship with universities. Thus, this study aimed to identify the main factors that motivate companies to establish this partnership. Hence, a descriptive study was elaborated, in which respondents are companies that have some level of cooperation with universities and institutes of science and technology. The results obtained show that the main reasons are, according to their importance: (1) to strengthen the technology, (2) to search for new sources of creativity, (3) to obtain expertise in market-oriented technologies, (4) to acquire new technologies; (5) to reach skilled labor, (6) to train their human resources, and (7) to develop new products. Furthermore, this study found that the less important factors are related to social reasons; this finding deserves further investigation in future studies.

KEY-WORDS: University-industry cooperation. Technological innovation. 


\section{INTRODUÇÃO}

A inovação tecnológica é considerada estratégica para que organizações e nações alcancem ou sustentem sua vantagem competitiva. Por meio dela é possível diferenciar-se dentre os concorrentes e ganhar novos mercados, gerar valor aos clientes e acionistas e também auferir maiores ganhos. Nesse sentido, Cruz (1999) atesta a importância de buscar a competitividade por meio da inovação, ressaltando a necessidade de valorizá-la ainda mais, especialmente no Brasil.

No país, a principal fonte de novos conhecimentos não está nas empresas, mas nas universidades e nos institutos de ciência e tecnologia (ICTs), diferentemente dos Estados Unidos, por exemplo, pois nesse país as empresas também têm um papel importante, ao contribuir para a geração de conhecimento, favorecendo a conversão em produtos e/ou serviços para a sociedade, por meio da inovação. Por outro lado, observa-se que, no modelo brasileiro, ainda é tênue a aproximação das instituições geradoras de conhecimento (universidades e ICTs) com as organizações que possuem o papel de transformação desses conhecimentos em produtos e serviços, apesar do inquestionável potencial de geração de valor que pode ser originado dessa relação.

Esse potencial pode ser verificado ao se fazer uma análise do crescimento das publicações científicas e tecnológicas, meio estratégico gerador de novos conhecimentos e inovação, eminentemente conduzidas no âmbito dos programas de pós-graduação stricto sensu no Brasil. Segundo a Capes (2010), no triênio de 2007 a 2009, o Brasil publicou 284.983 artigos em revistas científicas indexadas. Já em 2012, essa produção foi de 171.969, 34\% a mais em relação a 2010 (Capes, 2013).

Esse crescimento tem sido acompanhado pela expansão do sistema de pós-graduação stricto sensu no país. Em 2010, titularam-se 50.411 mestres e doutores, número que saltou para 60.910 em 2012 (Capes, 2013), representando um aumento de cerca de $20 \%$ em três anos. Esse potencial é verificado, portanto, por intermédio do aumento da produção intelectual em termos quantitativos e qualitativos, além da elevação do número de profissionais titulados nesses programas, que recebem formação 
para a condução de pesquisas científicas e tecnológicas nas instituições e organizações. Além disso, ressalte-se que esses atores podem assumir um importante papel na intermediação entre o meio acadêmico e o mercado, impulsionando o progresso tecnológico.

Com esse desenvolvimento, as possibilidades para as organizações usufruírem desses conhecimentos para aplicação prática são inquestionáveis. Conforme salientou Cruz (1999), a ciência não se transforma em tecnologia espontaneamente. Nesse sentido, o papel das empresas como produtoras de inovação ganha mais importância, tanto com relação à própria competitividade, quanto com relação à independência científica e tecnológica do país.

Assim sendo, a relação entre universidade e empresa torna-se uma questão estratégica, pois possibilita que a empresa transforme em inovação os conhecimentos criados pelas instituições de pesquisa, configurando, dessa maneira, uma relação ganha-ganha, que necessita ser estimulada e fortalecida. Para isso, Cruz (1999) afirma ser necessário que se crie uma cultura de pesquisa no meio empresarial.

Diante desse cenário, é possível observar iniciativas em que se estabelecem diversos níveis de parcerias universidade/ICTs e empresas. Nesse sentido, este estudo tem como pergunta de pesquisa: Quais os principais fatores que levam as empresas a buscar parcerias tecnológicas com os institutos de ciência e tecnologia? Para tanto, buscou-se alcançar o seguinte objetivo de pesquisa: Hierarquizar as razões que levam empresas à decisão de estabelecer parcerias com institutos de ciência e tecnologia. No Quadro 1, elencam-se as definições operacionais dos temos da pergunta de pesquisa.

\begin{tabular}{|c|l|}
\hline TERMO & \multicolumn{1}{c|}{ DEFINIÇÃo } \\
\hline \multirow{3}{*}{ Fatores } & $\begin{array}{l}\text { São os elementos motivadores por parte das empresas em termos das } \\
\text { seguintes categorias: (1) obtenção e compartilhamento de recursos em }\end{array}$ \\
& $\begin{array}{l}\text { Pesquisa e Desenvolvimento; (2) acesso a tecnologia e a suporte } \\
\text { tecnológico; (3) associação da imagem e para a prática de } \\
\text { responsabilidade social; (4) objetivos relacionados às questões mercado e } \\
\text { de desenvolvimento produtos (Porto, 2000, p. 74). }\end{array}$ \\
\hline
\end{tabular}

Continua 
Continuação

\begin{tabular}{|c|l|}
\hline Empresas & $\begin{array}{l}\text { São as organizações privadas que possuem processo de cooperação } \\
\text { formalizado com ICTs. }\end{array}$ \\
\hline $\begin{array}{c}\text { Parcerias } \\
\text { tecnológicas }\end{array}$ & $\begin{array}{l}\text { "Cooperação formal das empresas com universidades e institutos de } \\
\text { pesquisa, com o propósito de promover melhoria incremental ou radical, } \\
\text { em produtos ou processos, transferir tecnologia ou prestar serviço técnico } \\
\text { especializado, formalizada por meio de convênio, contrato ou outro } \\
\text { instrumento legal que define o objetivo da pesquisa e estabelece as } \\
\text { atribuições das partes, mesmo que de forma genérica, e indica um } \\
\text { horizonte temporal para que ela seja concluída" (Costa, Porto \& Feldhaus, } \\
\text { 2010, p. 110). }\end{array}$ \\
\hline $\begin{array}{c}\text { Institutos de } \\
\text { Ciência e } \\
\text { Tecnologia } \\
\text { (ICT) }\end{array}$ & $\begin{array}{l}\text { Órgão ou entidade da administração pública que tenha por missão } \\
\text { institucional, dentre outras, executar atividades de pesquisa básica ou } \\
\text { aplicada de caráter científico ou tecnológico. }\end{array}$ \\
\hline
\end{tabular}

\section{Quadro 1: Definições operacionais dos termos da pergunta de pesquisa}

A hierarquização tem como propósito identificar as principais razões que levam as organizações a estabelecerem parcerias com os ICTs. Essas razões foram agrupadas em conjuntos de elementos motivadores, denominados Fatores.

Este estudo justifica-se, pois, para que esse tipo de interação seja efetivado, é necessário entender os motivos pelos quais os atores envolvidos no processo buscam estabelecer parcerias. Esse entendimento poderá subsidiar o estabelecimento de políticas, mecanismos e ações que fomentem essas parcerias em seus diversos níveis.

\section{FUNDAMENTAÇÃO TEÓRICA}

\subsection{GESTÃO DA INOVAÇÃO}

Em um mundo globalizado onde empresas, corporações e até mesmo países competem ferozmente por clientes e mercados, ser inovativo é questão de sobrevivência. O Decreto 5.798, que regulamenta a Lei 11.196 (mais conhecida como a Lei do Bem) define inovação tecnológica como "a concepção de novo produto ou processo de fabricação, bem como a 
agregação de novas funcionalidades ou características ao produto ou processo que implique melhorias incrementais e efetivo ganho de qualidade ou produtividade, resultando maior competitividade no mercado" (Decreto $\mathrm{n}^{\circ} 5.798$, de 7 de junho de 2006).

As inovações tecnológicas em produtos e processos (TPP), de acordo com o Manual de Oslo, correspondem às implantações tecnologicamente novas ou às melhorias tecnológicas em produtos (bens e serviços) e processos (OECD, 2005, p. 23). Tidd, Bessant e Pavitt (2008, p. 30) definem inovação em produto como "mudança nas coisas (produtos/serviços) que uma empresa oferece" e inovação de processo como "mudanças na forma em que os produtos/serviços são criados e entregues".

A implantação ocorre somente quando estiver introduzida no mercado (inovação de produto) ou usada no processo de produção (inovação de processo), envolvendo uma série de atividades científicas, tecnológicas, organizacionais, financeiras e comerciais. Para ser considerada inovadora em TPP, é necessário que a empresa, durante o período de análise, tenha implantado produtos ou processos tecnologicamente novos ou com substancial melhoria tecnológica, sem a necessidade de que seja inédito no mundo (OECD, 2005, p. 70).

A inovação não é realizada aleatoriamente e, por tratar-se de um processo de alta complexidade, alto risco e incerteza, faz-se necessário o emprego de procedimentos e metodologias adequados e um sistema eficiente para produzir os resultados objetivados pela empresa. Esse processo deve ser gerenciado de maneira criteriosa de modo a produzir resultados, como tornar invenções em inovações, isto é, em produtos comercialmente viáveis no mercado (Freeman \& Soete, 1997, p. 6).

A gestão da inovação é um processo organizacional que, segundo Tidd et al. (2008), envolve três pilares básicos - conhecimento, informação e criatividade -, a partir dos quais são geridas integradamente as alternativas lucrativas de (mais) valor (novas tecnologias). Afirmam os autores que os seguintes processos são considerados essenciais para alcançar resultados inovadores: planejamento, alocação, organização e coordenação de fatores. 
Complementarmente, ao abordar o processo de inovação de uma maneira estruturada, é necessário que a empresa defina inicialmente um posicionamento estratégico, a partir do qual será lançada uma estratégia de inovação com as principais metas a serem atingidas no escopo de lançar produtos inovadores para conquistar mercados, maior rentabilidade e satisfação dos stakeholders. O conceito moderno de gestão de inovação transcende os limites dos departamentos de pesquisa e desenvolvimento, envolvendo todas as interfaces da organização (Jonash \& Sommerlatte, 2011). É um processo cultural e contínuo, em que os três pilares anteriormente mencionados interagem sinergicamente.

Uma vez que a criação de projetos inovadores envolve a geração de conhecimento, pode o gestor de inovação buscá-lo no ambiente interno ou externo à empresa. No último caso, alguns meios possíveis podem ser parcerias estratégicas, licenciamento de tecnologias e joint ventures (Hitt, Ireland \& Hoskisson, 2012), característica de organizações que se voltam para a inovação aberta (open innovation), por meio da transição de um modelo de inovação interna pura para um modelo que passa a incluir a colaboração com instituições e organizações do ambiente externo buscando fomentar a pesquisa, o desenvolvimento e a inovação (Enkel, Gassmann \& Chesbrough, 2009). Neste estudo, o foco recai especificamente sobre a parceria de empresas com ICTs e universidades, e seu respectivo processo de interação.

Segundo o Manual de Oslo (OECD, 2005, p. 93), a inovação cooperativa, que é definida como "cooperação ativa com outras empresas ou instituições públicas de pesquisa para atividades de inovação (que podem incluir compras de conhecimento e de tecnologia)", permite acesso a conhecimentos e tecnologias por empresas que não possuem condições de explorá-los sozinhas. Ademais, apresenta potencial para sinergias de cooperação, com aprendizado mútuo, representando uma relação "ganhaganha".

Destaque-se que a empresa, conforme afirmaram Stal, Campanário, Andreassi e Sbragia (2006, p. 19), deve estar inserida num Sistema Nacional de Inovação (SNI), que é definido como: 
Uma rede de instituições públicas e privadas que interagem para promover o desenvolvimento científico e tecnológico de um país. Inclui empresas, dos mais variados tipos, associações empresariais, universidades, escolas técnicas, institutos de pesquisa, governo, agências de fomento e agências reguladoras, num esforço de geração, importação, modificação, adaptação e difusão de inovações tecnológicas.

Conforme esses autores, o Triângulo de Sábato é uma das primeiras representações do SNI, cujos vértices são (1) o governo, (2) as instituições de ensino e pesquisa, e (3) as empresas, em que cada um assume um papel específico. De acordo com Figueiredo (1993), o Triângulo de Sábato pode ser visto como uma estratégia de ação para possibilitar o progresso científico-tecnológico de países, resultado da ação sinérgica entre esses três elementos, que se inter-relacionam.

Stal et al. (2006) sustentam que, do Triângulo de Sábato, surgiu a metáfora da hélice tripla, que consiste na existência de uma intersecção entre as hélices. Cada uma representa uma esfera institucional independente, porém, todas trabalham em cooperação e interdependência. Conforme Etzkowitz (2003), o modelo é mais interativo e interdisciplinar, contrastando com a forma linear de inovação, aproximando os diversos atores e permitindo que haja um processo de hibridização entre as diferentes esferas.

De acordo com Etzkowitz e Leydesdorff (2000), o modelo relacional entre os agentes deixa de ser bidirecional e considera-se que os três agentes passam a atuar concomitantemente de maneira sinérgica na hélice tripla, passando para um modelo trilateral de relações. Conforme observaram os autores, a tese da hélice tripla é pautada na ideia de que a universidade desempenha um papel mais importante e atuante no processo de inovação, ao cumprir a função de transferência de conhecimentos e tecnologias para a sociedade.

\subsection{INTERAÇÃO ICT-EMPRESA}

O relacionamento com universidades é considerado um dos mais efetivos meios de obtenção de inovação tecnológica pelas organizações (Reis, 1998). Por meio do conhecimento gerado nas instituições de pesquisas, as empresas têm a possibilidade de suprir suas necessidades em 
desenvolvimento de produtos, serviços e aprimoramento de processos, como uma alternativa a um investimento interno de pesquisa que, em muitos casos, é inviável devido ao nível de investimento necessário.

Segundo Plonski (1995), as empresas percebem essa cooperação como um meio capaz de prover soluções para atividades complexas e multidimensionais, como ocorre na inovação. Dessa forma, o autor relatou que as organizações buscam: capacitar e especializar os recursos humanos; obter apoio de assessorias para o aperfeiçoamento da qualidade e da produtividade; adaptar-se aos requisitos da legislação do consumidor e de preservação ambiental; e desenvolver novos produtos e processos. Adicionalmente, também procuram obter acesso privilegiado para recrutar e selecionar novos talentos.

Para Plonski (1998), a expressão "cooperação universidadeempresa" envolve diversos atores. A "empresa" é geralmente pessoa jurídica, desde transacionais até microempresas, mas que pode ser pessoa física (inventor), uma empresa informal ou cooperativa. Por outro lado, o termo "universidade" representa uma instituição de ensino superior, como universidades, centros universitários ou faculdades isoladas, públicas ou privadas. Também pode ser uma entidade conveniada ou associada a elas, como hospitais, institutos de pesquisa, fundações e empresas juniores.

Portanto, os dois principais atores nessa relação são as empresas e, por outro lado, as universidades, que desempenham um papel importante nesse processo. Tanto é que, conforme Marcovitch (1999), para que a cooperação ocorra em termos ideais, faz-se necessário que a universidade contribua de forma efetiva na modernização dos processos produtivos.

Nesse sentido, o autor destaca a importância do papel da universidade no que diz respeito à (1) formação de quadros (graduação) para o mercado, primeiro nível de interação universidade-empresa; (2) importância do papel da pós-graduação stricto sensu para a inovação, o avanço tecnológico e o desenvolvimento, diferencial do novo século para países globalizados; e (3) necessidade de desmistificação de que o pesquisador acadêmico é demasiado teórico e de que o empresário normalmente despreza a pesquisa. Especificamente com relação à pósgraduação, Marcovitch (1999, p. 13) afirma que "sendo o suporte principal 
para o desenvolvimento da produção científico-tecnológica em nosso país, o sistema público de pesquisa, fruto da Pós-Graduação, tem cumprido o seu papel, não obstante suas notórias dificuldades".

Conceitualmente, Plonski (1995) definiu a cooperação universidadeempresa como um arranjo interinstitucional, composto por organizações de natureza distinta. Esse arranjo tem diversos formatos e finalidades, que vão desde interações tênues, como ocorre no oferecimento de estágios, até vínculos mais intensos, como nos grandes programas de pesquisa cooperativa. Complementarmente, Costa et al. (2010, p. 110) o definiram como:

Cooperação formal das empresas com universidades e institutos de pesquisa, com o propósito de promover melhoria incremental ou radical, em produtos ou processos, transferir tecnologia ou prestar serviço técnico especializado, formalizada por meio de convênio, contrato ou outro instrumento legal que define o objetivo da pesquisa e estabelece as atribuições das partes, mesmo que de forma genérica, e indica um horizonte temporal para que ela seja concluída.

O processo de cooperação pode atingir alta complexidade, pois apresenta diversos formatos e finalidades e, além disso, pode assumir variações no grau de relações entre as partes. Nesse sentido, SegattoMendes e Sbragia (2002) ressaltaram a necessidade de segmentar o processo em etapas (Figura 1), de modo que seja possível realizar uma análise mais adequada, minuciosa e profunda em cada aspecto considerado.

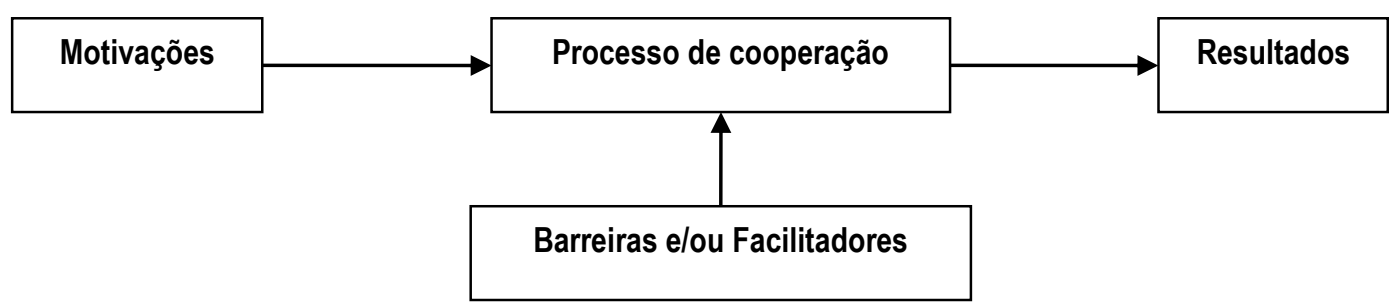

Figura 1: Modelo teórico do processo de cooperação universidadeempresa

Fonte: Seggato-Mendes e Sbragia (2002)

Esse modelo proposto pelos autores, que parte da estrutura teórica de Bonaccorsi e Piccaluga (1994), identifica as diferentes fases do processo de interação que está relacionado a diferentes aspectos em momentos 
distintos. As motivações ao processo são a fase inicial e, durante o processo de cooperação, há a influência de facilitadores e/ou barreiras que influenciam e determinam os resultados dessa interação. Vale ressaltar que, conforme os autores, entender as motivações é essencial para que se possam comparar, num segundo momento, os resultados alcançados, o que permite uma análise mais adequada e abrangente do processo. Para fins desta pesquisa, será dado foco à primeira parte do processo, buscando entender melhor as questões relacionadas às motivações das empresas para estabelecer parcerias.

No estudo realizado por Costa (1998), os motivos pelos quais as empresas buscam estabelecer parcerias foram: potencializar os investimentos; aperfeiçoar suporte tecnológico; organizar a produção em escala global; associar a dimensão tecnológica para o desempenho econômico, embasada no conhecimento científico. Para isso, elas buscam: recursos humanos qualificados, suportes técnicos de excelência e acesso aos laboratórios, para acompanhar os acontecimentos científicos e tecnológicos. Segatto-Mendes (1996) lista as motivações das empresas para estabelecer relações:

- carência de recursos humanos para desenvolver as próprias pesquisas;

- permissão de acesso às fronteiras científicas do conhecimento;

- acesso aos recursos universitários (laboratórios, bibliotecas, instrumentos, etc.);

- redução do prazo necessário para o desenvolvimento de tecnologia;

- licença para explorar tecnologia estrangeira pode ser uma despesa muito maior que contratar pesquisa universitária;

- existência de pesquisas anteriores por meio da cooperação que obtiveram resultados satisfatórios;

- contato com o meio universitário, que permite estimular a criatividade científica dos funcionários de $P$ \& D;

- divisão do risco; 
- melhoria da imagem pública da empresa através de relações com universidades;

- identificação de estudantes para recrutamento/seleção.

Ressalte-se, de acordo com Segatto-Mendes (1996), que existe também a preocupação com relação à imagem pública das organizações, um aspecto contemporâneo e distinto das tradicionais razões pelas quais empresas buscam parcerias. Adicionalmente, Bonaccorsi e Piccaluga (1994) elencaram as motivações (Quadro 2), consoante as constatações de Costa (1998) e Segatto-Mendes e Sbragia (2002).

\begin{tabular}{|c|c|}
\hline \multicolumn{2}{|r|}{ Motivações para as empresas } \\
\hline $\begin{array}{l}\text { Conseguir } \\
\text { acesso à } \\
\text { fronteira } \\
\text { científica }\end{array}$ & $\begin{array}{l}\text { Obter acesso antecipado aos pontos de quebra científicos; } \\
\text { Obter informação do estado da arte; } \\
\text { Manter múltiplas direções de pesquisa sob condições de tecnologia pré- } \\
\text { paradigmática; } \\
\text { Contratação de recursos humanos altamente qualificados já habilitados } \\
\text { em atividades de pesquisa em tecnologias no estado da arte; } \\
\text { Dar ao pessoal pesquisador interno a oportunidade de trocas de alto } \\
\text { nível científico e estimular a criatividade dos recursos internos de P\&D } \\
\text { através da exposição à pesquisa acadêmica; } \\
\text { Manter uma "janela aberta" sobre pesquisa fundamental pura (não } \\
\text { orientada); } \\
\text { Beneficiar-se de descobertas ocasionais, inesperadas, típicas da } \\
\text { atividade de pesquisa; } \\
\text { Construir centros de excelência; } \\
\text { Tomar o acesso ao conhecimento mais difícil para os concorrentes. }\end{array}$ \\
\hline $\begin{array}{l}\text { Aumentar a } \\
\text { capacidade de } \\
\text { previsão da } \\
\text { ciência }\end{array}$ & $\begin{array}{l}\text { Estimular o desenvolvimento de modelagem matemática para as } \\
\text { atividades de criação e solução de problemas; } \\
\text { Separar e partilhar atividades selecionadas com o objetivo de trocar } \\
\text { dados técnicos; } \\
\text { Obter treinamento e apoio para desenvolver habilidades internas. }\end{array}$ \\
\hline $\begin{array}{l}\text { Delegar } \\
\text { atividades de } \\
\text { desenvolvimento } \\
\text { selecionadas }\end{array}$ & $\begin{array}{l}\text { Partilhar riscos; } \\
\text { Diminuir custos; } \\
\text { Resolver problemas localizados de projetos industriais; } \\
\text { Evitar investimentos vultosos em equipamentos que terão baixas taxas } \\
\text { de utilização; } \\
\text { Obter acesso a grandes escalas de experimentação e testes. }\end{array}$ \\
\hline $\begin{array}{l}\text { Falta de } \\
\text { recursos }\end{array}$ & $\begin{array}{l}\text { Obter acesso a facilidades universitárias (laboratórios, instrumentação, } \\
\text { biblioteca); } \\
\text { Alcançar a escala de gestão eficiente de facilidades de pesquisa; } \\
\text { Obter acesso rápido a novas áreas do conhecimento; } \\
\text { Melhorar a imagem da organização. }\end{array}$ \\
\hline
\end{tabular}

\section{Quadro 2: Motivações para as empresas}

Fonte: Bonaccorsi e Piccaluga (1994, citado por Reis, 1998) 
Conforme Bonnacorsi e Piccaluga (1994), o bloco de motivações "conseguir acesso à fronteira científica" representa o mais relevante sob condições da dependência da tecnologia e no estado da arte científica, representando o aumento da importância e do número de pesquisas multidisciplinares. Assim sendo, relatam que a manutenção de relações próximas com universidades deve ser parte de uma estratégia tecnológica e de pesquisa e desenvolvimento das empresas.

\section{ASPECTOS METODOLÓgICOS}

Segundo Vergara (2009), a pesquisa é classificada quanto aos fins e quanto aos meios. Quanto aos fins, trata-se de um estudo quantitativodescritivo que, conforme Marconi e Lakatos (1996, p. 86), "consiste em investigações de pesquisa empírica cuja finalidade é o delineamento ou análise das características de fatos ou fenômenos". Gil (1998) complementa que a pesquisa descritiva também expõe características de uma população. Quanto aos meios, a pesquisa é caracterizada por ser: bibliográfica, pelo fato de possuir uma fase de consulta a livros, periódicos, anais, teses e dissertações; desk research, com a consulta a outras fontes de informação; e de campo, por realizar o levantamento de dados primários junto aos respondentes.

O universo da pesquisa corresponde às empresas integrantes da Associação Nacional de Pesquisa e Desenvolvimento das Empresas Inovadoras (Anpei), que conta atualmente com 151 empresas associadas. São empresas de média e alta intensidade tecnológica, pertencentes principalmente aos setores de Serviços Tecnológicos (19\%), Químico $(13 \%)$, Máquinas e Equipamentos (12\%), Eletroeletrônico (7\%) e de Autopeças (7\%); mais da metade (55\%) é de grande porte (acima de 500 empregados); a maioria $(26,5 \%)$ é de capital nacional e, juntas, somaram $\mathrm{R} \$ 10$ bilhões em investimento em P,D\&I no Brasil (Anpei, 2015).

A amostragem foi do tipo não probabilístico, por acessibilidade aos e-mails dos representantes de tais organizações. Como critério de qualificação, as empresas deveriam ter, ou já terem mantido, parcerias com 
ICTs e universidades. A quantidade de respostas afirmativas obtidas foi de 38 empresas, perfazendo $25,2 \%$ do universo.

Foram elaboradas questões com perguntas fechadas, com as seguintes partes: caracterização do respondente e da empresa, com 23 questões; fatores motivadores, com 26 questões. Esta última parte do instrumento de coleta foi construída tendo como base a classificação dos quatro fatores motivadores para empresas proposta na tese de Porto (2000, p. 74-75), a saber: pesquisa e desenvolvimento; tecnologia; produto/mercado; contribuição social. Estes foram adaptados aos objetivos da presente pesquisa, sendo apresentados na forma de escala Likert de quatro pontos. Os respondentes foram expostos a 23 sentenças afirmativas.

Por se tratar de uma survey (levantamento), o método de coleta de dados primários ocorre por meio de aplicação de questionários autorrespondidos (Hair Jr et al., 2007). Segundo Martins e Theóphilo (2009, p. 60), o levantamento é apropriado para os "casos em que o pesquisador deseja responder a questões acerca da distribuição de uma variável ou das relações entre características de pessoas ou grupos, da maneira como ocorrem as situações naturais". Dessa maneira, essa estratégia de pesquisa mostra-se apropriada para os propósitos desta pesquisa.

Para a coleta de dados, foi elaborado questionário eletrônico (esurvey), cujo acesso foi enviado aos respondentes por e-mail, com a disponibilização do link aos respondentes. Para tratamento e análise dos dados, foram utilizadas as ferramentas do Microsoft Excel (tabela dinâmica, gráficos), buscando-se analisar a frequência das respostas e evidenciar possíveis associações entre as variáveis pesquisadas.

\section{APRESENTAÇÃO E ANÁLISE DOS DADOS}

\subsection{RESPONDENTES}

Foi obtido o total de 38 questionários, cuja maioria dos respondentes pertence ao gênero masculino (84\%). Com relação à idade, oito respondentes têm idade abaixo de 30 anos; oito, entre 31 e 40 anos; 
13, entre 41 e 50 anos; nove acima de 51 anos, indicando grau de senioridade dos profissionais.

A área de formação predominante é a de engenharias

respondentes). Com relação à experiência profissional, oito estão na faixa de $0-10$ anos; 12 , entre 11-20; 15, entre 21-30; e três, acima de 30 anos. Ressalte-se que 15 respondentes afirmaram ter experiência específica na relação entre universidades/ICTs e empresas, cujo tempo médio é de 11,3 anos nesse tipo de atuação.

Com relação à formação, 75\% possuem pós-graduação e somente $5 \%$ possuem superior incompleto, indicando, dessa maneira, alto nível de qualificação dos respondentes. Esse indicador pode ser explicado pelo cargo que ocupam nas organizações - mais de $60 \%$ dos respondentes ocupam níveis gerenciais ou acima.

Com relação à área funcional, 15 respondentes pertencem à área de pesquisa e desenvolvimento; sete, à de vendas e exportação; quatro, à área de produção; três, à de entregas de serviços. Ademais, as seguintes áreas também foram citadas: governança corporativa, projetos corporativos, marketing, tecnologia da informação, instrumentação e gestão da inovação.

\subsection{EMPRESAS}

As organizações representadas atuam no Brasil há muito tempo: dez operam há pelo menos 50 anos; 13, entre 40 e 50 anos; dez, entre 10 e 20 anos; e cinco, há menos de 10 anos. Com relação ao tempo de interação entre universidades e ICTs, mais da metade da amostra (55\%) mantém esse tipo de cooperação há mais de dez anos (Gráfico 1). 


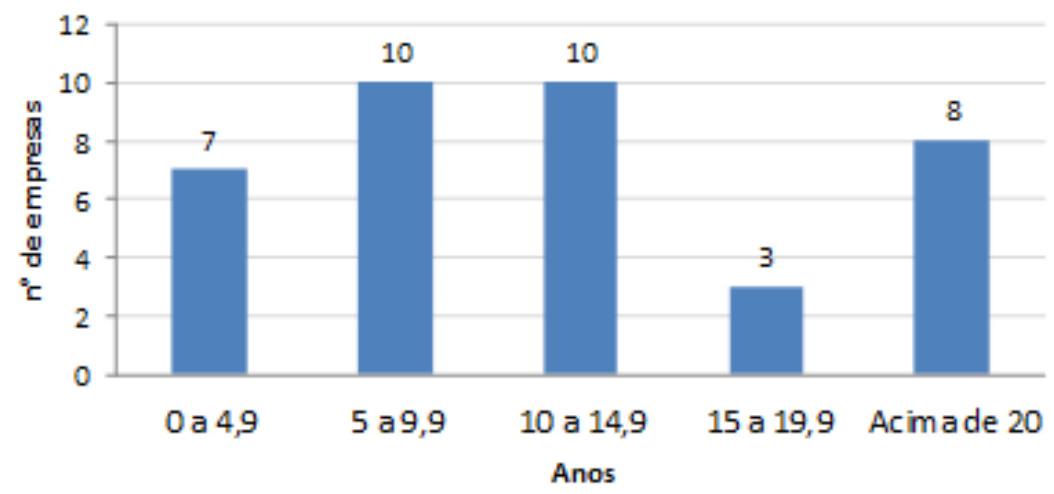

\section{Gráfico 1: Duração das parcerias com ICTs}

O principal setor de atuação das empresas pesquisadas é o automotivo (12 empresas), vem, em seguida, o setor de telecomunicações, mídia e tecnologia (quatro empresas), representando dois setores cujos produtos possuem alto valor agregado devido à inovação e tecnologias empregadas.

Tabela 1: Tempo de interação por setor

\begin{tabular}{l|c|lc}
\hline \multicolumn{1}{c|}{ Setor ( $\mathrm{n}^{\circ}$ empresas) } & Anos (média) & \multicolumn{1}{c}{ Setor ( $\mathrm{n}^{\circ}$ empresas) } & Anos \\
\hline Automotivo (12) & 12,5 & Aviação (1) & 42 \\
\hline Tecnologia, mídia e telecomunicações (4) & 8,5 & Construção civil (1) & 1 \\
\hline Cosméticos (3) & 9 & Educação (1) & 3 \\
\hline Serviços (3) & 11,7 & Internet (1) & 5 \\
\hline Alimentos (2) & 4,5 & Mineração (1) & 15 \\
\hline Energia (2) & 30,0 & Petroquímico (1) & 10 \\
\hline Outros (3) & 7,0 & Máquinas e equipamentos (1) & 6 \\
\hline & & Químico (1) & 5 \\
\hline & & Siderurgia (1) & 15 \\
\hline
\end{tabular}

Com relação ao tamanho das empresas, dez têm até 500 funcionários; 11, de 501 a 2.000; e 17 têm mais 2.000 colaboradores. Esses dados demonstram que predominam grandes empresas, fato que pode ser constatado no faturamento anual: 25 auferem mais de 60 milhões de reais por ano de receita operacional bruta. Em sua maioria são empresas privadas (34), cujo capital controlador é praticamente equivalente entre o capital nacional (17) e o estrangeiro (16).

Com relação à personalidade jurídica das universidades e ICTs com os quais as empresas mantêm relacionamento, 19 são públicas e 16 são 
mistas (publico/privada). Note-se que é baixa a incidência de instituições dessa natureza de caráter eminentemente privado (3).

Praticamente a metade das empresas exporta produtos ou já implantou inovações originadas de parcerias no país com universidades/ICTs em subsidiárias no exterior e, além disso, cinco pretendem realizar esse tipo de transferência.

A maioria das empresas (25) afirma manter algum tipo de estrutura formalizada para lidar com a parceria, enquanto 12 não o fazem. Com relação aos propósitos da parceria, as empresas pesquisadas buscam prioritariamente criar inovação em produtos e/ou processo (28 e 29 respectivamente), sendo a busca por inovação em serviços menos frequente.

Das 21 empresas que adotam parcerias por pelo menos 10 anos, 17 (81\%) dispõem de estruturas formais para lidar com esse tipo de parceria, tais como departamentos ou instruções normativas. Das 17 empresas que adotam parcerias por menos de 10 anos, oito (48\%) mantêm essas estruturas.

\subsection{FATORES MOTIVADORES}

Para atender ao objetivo de pesquisa, que é o de hierarquizar as razões que levam empresas à decisão de estabelecer parcerias com ICTs, são apresentados os resultados conforme as seguintes categorias: Pesquisa e Desenvolvimento, Tecnologia, Produto/Mercado e Contribuição Social.

\subsubsection{Pesquisa e Desenvolvimento}

De acordo com os resultados da pesquisa (Tabela 2), os principais motivos que levaram as empresas pesquisadas a estabelecer relações com ICTs foram: a busca por novas fontes de criatividade, o acesso à mão de obra qualificada e a capacitação de seus recursos humanos. Note-se que esses três fatores obtiveram os maiores resultados, tanto na ordenação pelo número de respostas "Concordo Totalmente" (CT), quanto pela soma das respostas "Concordo Totalmente" e "Concordo Parcialmente" (CP). Ademais, 
apresentaram baixo número de discordância, representando, dessa maneira, os três principais motivos dessa categoria.

Tabela 2: Categoria Pesquisa e Desenvolvimento, ordenadas por CT

\begin{tabular}{|c|c|c|c|c|c|c|c|}
\hline \multirow[b]{2}{*}{ Categoria } & \multicolumn{6}{|c|}{ Resultados } & \multirow[b]{2}{*}{ Item } \\
\hline & CT & $\mathrm{CP}$ & $\begin{array}{c}\mathrm{CT} \\
+ \\
\mathrm{CP}\end{array}$ & DP & DT & $\begin{array}{c}\text { DT } \\
+ \\
\text { DP }\end{array}$ & \\
\hline \multirow{9}{*}{ 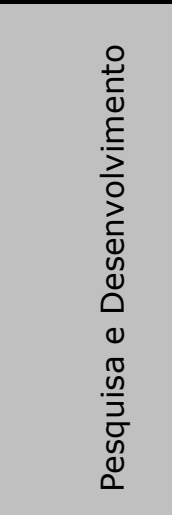 } & 25 & 10 & 35 & 2 & 1 & 3 & Busca de novas fontes de criatividade \\
\hline & 21 & 16 & 37 & 1 & 0 & 1 & Acesso a mão de obra qualificada \\
\hline & 21 & 15 & 36 & 1 & 1 & 2 & Capacitação de seus recursos humanos \\
\hline & 19 & 11 & 30 & 8 & 0 & 8 & Redução tempo de desenv. prod./ proc./serv. \\
\hline & 12 & 16 & 28 & 7 & 3 & 10 & Acesso às instalações das universidades \\
\hline & 10 & 13 & 23 & 6 & 9 & 15 & Acesso a recursos financeiros governamentais \\
\hline & 7 & 15 & 22 & 10 & 6 & 16 & Diminuição dos gastos internos com P\&D \\
\hline & 5 & 25 & 30 & 4 & 4 & 8 & Diminuição dos riscos envolvidos em P\&D \\
\hline & 4 & 18 & 22 & 12 & 4 & 16 & Compartilhamento das instalações de P\&D \\
\hline
\end{tabular}

Legenda: CT - Concordo Totalmente; CP - Concordo Parcialmente; DP - Discordo Parcialmente; DT - Discordo Totalmente

Ressalte-se que os fatores "diminuir os gastos internos com P\&D" e "compartilhar suas instalações de P\&D" obtiveram os menores valores com relação à soma das respostas de concordância, e maiores com relação à soma das respostas de discordância, "Discordo Totalmente" (DT) e "Discordo Parcialmente" (DP), o que indica que nem todas as organizações pesquisadas buscam redução de custo ou compartilhamento de estruturas.

\subsubsection{Tecnologia}

Com relação à categoria Tecnologia, os dois principais motivos são o fortalecimento de sua tecnologia e a aquisição de novas tecnologias que, conforme a Tabela 3, foram os itens com maiores índices de concordância total, soma de CT + CP e menores valores de discordância. 
Tabela 3: Categoria Tecnologia, ordenadas por CT

\begin{tabular}{|c|c|c|c|c|c|c|c|}
\hline \multirow[b]{2}{*}{ Categoria } & \multicolumn{6}{|c|}{ Resultados } & \multirow[b]{2}{*}{ Item } \\
\hline & CT & $\mathrm{CP}$ & $\begin{array}{c}\mathrm{CT} \\
+ \\
\mathrm{CP}\end{array}$ & DP & DT & $\begin{array}{c}\text { DT } \\
+ \\
\text { DP }\end{array}$ & \\
\hline \multirow{5}{*}{$\begin{array}{l}\frac{0}{\overline{0}} \\
\frac{0}{0} \\
\stackrel{\complement}{ \pm} \\
\stackrel{0}{-}\end{array}$} & 26 & 8 & 34 & 4 & 0 & 4 & Fortalecimento da tecnologia \\
\hline & 24 & 12 & 36 & 2 & 0 & 2 & Aquisição de novas tecnologias \\
\hline & 18 & 12 & 30 & 6 & 2 & 8 & Acesso ao suporte técnico de excelência \\
\hline & 13 & 17 & 30 & 7 & 1 & 8 & Obtenção de informações específicas \\
\hline & 11 & 18 & 29 & 8 & 1 & 9 & Resolução de um problema específico \\
\hline
\end{tabular}

Legenda: CT - Concordo Totalmente; CP - Concordo Parcialmente; DP - Discordo Parcialmente; DT - Discordo Totalmente

Ressalte-se que, ao analisar o conjunto das respostas de $\mathrm{CT}+\mathrm{CP}$, todos obtiveram alto índice de concordância (no mínimo 29, ou 74\%), o que significa que a categoria tecnologia é um importante motivo para as empresas estabelecerem parcerias com ICTs. Note-se também que, dentre os itens analisados, a obtenção de informações ou a resolução de problemas específicos foram os motivos que apresentaram menor frequência (CT).

\subsubsection{Produto/Mercado}

Nesta categoria (Tabela 4), os fatores que obtiveram maior número de respostas CT foram "obter expertise em tecnologias para o mercado" e "desenvolver novos produtos", que também obtiveram os maiores índices de concordância $(C T+C P)$ e, consequentemente, os menores índices de discordância. 
Tabela 4: Categoria Produto/Mercado, ordenadas por CT

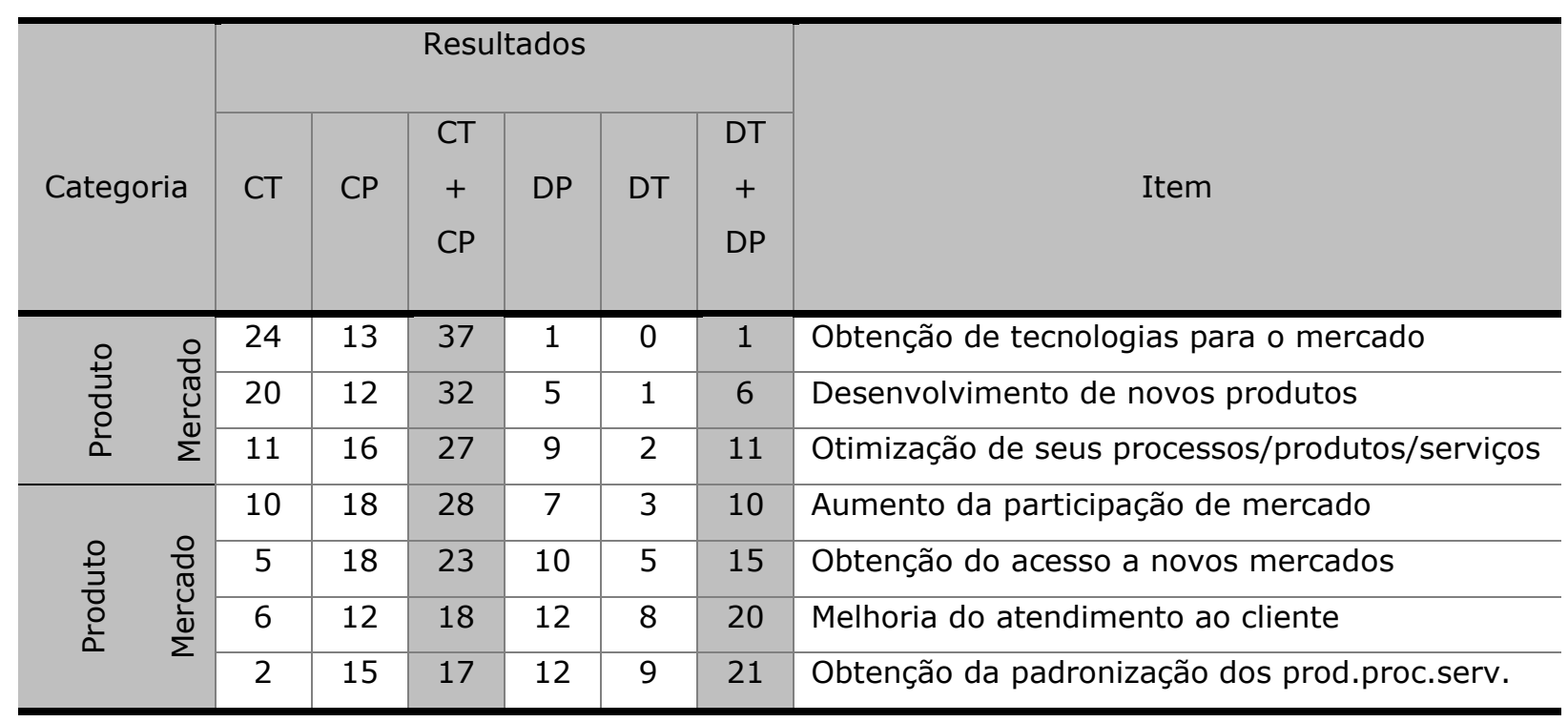

Legenda: CT - Concordo Totalmente; CP - Concordo Parcialmente; DP - Discordo Parcialmente; DT - Discordo Totalmente

Por outro lado, os fatores com menores índices de concordância foram "melhorar seu atendimento ao cliente" e "obter padronização de seus produtos, processos e serviços".

\subsubsection{Contribuição Social}

Nesta categoria (Tabela 5), os fatores que obtiveram os maiores índices de concordância foram "obter prestígio e melhorar a imagem" e "contribuir para as boas relações comunitárias". 
Tabela 5: Categoria Contribuição Social, ordenadas por CT

\begin{tabular}{|c|c|c|c|c|c|c|c|}
\hline \multirow[b]{2}{*}{ Categoria } & \multicolumn{6}{|c|}{ Resultados } & \multirow[b]{2}{*}{ Item } \\
\hline & CT & $\mathrm{CP}$ & $\begin{array}{l}\mathrm{CT} \\
+ \\
\mathrm{CP}\end{array}$ & DP & DT & $\begin{array}{l}\text { DT } \\
+ \\
\text { DP }\end{array}$ & \\
\hline \multirow{5}{*}{ 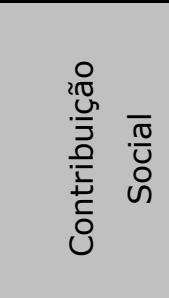 } & 11 & 13 & 24 & 10 & 4 & 14 & Obtenção de prestígio e melhoria da imagem \\
\hline & 10 & 12 & 22 & 12 & 4 & 16 & Contribuição para as boas relações comunitárias \\
\hline & 6 & 19 & 25 & 9 & 4 & 13 & Melhoria da imagem junto ao grande público \\
\hline & 5 & 11 & 16 & 15 & 7 & 22 & Resolução de problemas ambientais \\
\hline & 4 & 12 & 16 & 11 & 11 & 22 & Transferência internacional de tecnologias \\
\hline
\end{tabular}

Legenda: CT - Concordo Totalmente; CP - Concordo Parcialmente; DP - Discordo Parcialmente; DT - Discordo Totalmente

Verifique-se que houve alto índice de discordância (DT+DP) com relação à resolução de problemas ambientais e com respeito à transferência internacional de tecnologias, em comparação às concordâncias ( $C T+C P)$, indicando, dessa maneira, haver maior interesse quanto a imagem, prestígio e relações com a comunidade em comparação às questões ambientais e tecnológicas.

\subsection{DISCUSSÃO}

A partir dos resultados obtidos pelo questionário, foi possível elencar os principais fatores que levam as empresas a buscarem parecerias com ICTs e universidade.

Para análise e interpretação dos dados, utilizou-se o estudo das frequências, a partir do percentual das respostas assinaladas. Para tanto, foram consideradas as respostas concordo totalmente (CT) e discordo totalmente (DT), como critério. Os maiores resultados obtidos de concordância absoluta (CT) são apresentados em percentuais na Tabela 6.

No topo da hierarquia dos motivos está, dentro da categoria Tecnologia, a adoção de parcerias para busca do fortalecimento da tecnologia da própria empresa, com uma concordância de 68\% dos respondentes. De toda a amostra pesquisada, nenhuma empresa respondeu que discordava totalmente dessa afirmação. Esse fato corrobora a 
afirmação de Reis (1998) de que esse tipo de parceria é uma importante fonte de acesso a tecnologia e inovação.

Em segundo lugar, está a busca de novas fontes de criatividade, dentro da categoria Pesquisa e Desenvolvimento. Com relação à primeira variável motivacional apresentada, há um índice de discordância de 3\%.

A seguir, encontram-se em um mesmo patamar de aceitação as variáveis que encerram a busca de novas tecnologias, tanto em termos da obtenção da própria tecnologia em si (categoria Tecnologia) como quanto à expertise para lidar com esta nova tecnologia (categoria Produto/Mercado). Ressalte-se que novamente não houve rejeição por parte de nenhuma empresa para essas variáveis (DT $=0 \%$ ), reforçando, novamente, a afirmação de Reis (1998).

Em quinto lugar, o acesso à mão de obra aparece com um índice de concordância de $55 \%$ dentre os respondentes. Com esse mesmo percentual está a capacitação dos recursos humanos da própria empresa. A diferença para classificar uma como quinta e outra como sexta reside no percentil de rejeição de 3\% desta última variável. Ambas as variáveis encontram-se dentro da categoria Pesquisa e Desenvolvimento. Esse fato corrobora as afirmações de autores como Bonaccorsi e Piccaluga (1994), Segatto-Mendes (1996), Costa (1998) e Porto (2000), de que esse tipo de relação é um meio importante de capacitação, recrutamento e acesso a recursos humanos qualificados.

Por fim e em sétima posição, está a busca de parcerias com o propósito de desenvolver novos produtos, dentro da categoria Produto/Mercado. Esta variável, assim como todas as primeiras, apresenta um índice de concordância de mais de 50\%. 
Tabela 6: Principais fatores motivadores

\begin{tabular}{|c|c|c|c|c|}
\hline \multirow{2}{*}{ Posição } & \multirow{2}{*}{ Variável } & \multirow{2}{*}{$\begin{array}{l}\text { Categoria à qual } \\
\text { pertence }\end{array}$} & \multicolumn{2}{|c|}{ Percentual de respostas } \\
\hline & & & CT & DT \\
\hline 10 & Fortalecer sua tecnologia & Tecnologia & $68 \%$ & $0 \%$ \\
\hline $2^{\circ}$ & Novas fontes de criatividade & $\begin{array}{c}\text { Pesquisa e } \\
\text { Desenvolvimento }\end{array}$ & $66 \%$ & $3 \%$ \\
\hline \multirow[t]{2}{*}{$30 / 40$} & $\begin{array}{l}\text { Obter expertise em tecnologias } \\
\text { para o mercado }\end{array}$ & Produto/Mercado & $63 \%$ & $0 \%$ \\
\hline & Adquirir novas tecnologias & Tecnologia & $63 \%$ & $0 \%$ \\
\hline 50 & $\begin{array}{l}\text { Acesso a mão de obra } \\
\text { qualificada }\end{array}$ & $\begin{array}{c}\text { Pesquisa e } \\
\text { Desenvolvimento }\end{array}$ & $55 \%$ & $0 \%$ \\
\hline 60 & $\begin{array}{l}\text { Capacitação de seus recursos } \\
\text { humanos }\end{array}$ & $\begin{array}{c}\text { Pesquisa e } \\
\text { Desenvolvimento }\end{array}$ & $55 \%$ & $3 \%$ \\
\hline 70 & Desenvolver novos produtos & Produto/Mercado & $53 \%$ & $3 \%$ \\
\hline
\end{tabular}

Os resultados apresentados na Tabela 6 permitem observar que todas essas motivações concentram mais de 50\% (20 respondentes ou mais, em termos absolutos) das respostas de concordância total.

Os dados demonstram que os fatores apresentados tiveram um alto nível de aceitação entre os entrevistados. Esse resultado é corroborado pelo fato de que, dentre todos os sete primeiros motivos para a adoção de parcerias, no máximo $3 \%$ dos entrevistados responderam que discordavam totalmente.

Por meio desses achados, é possível observar que as organizações possuem características da inovação aberta, em que o centro de pesquisa e desenvolvimento não se restringe unicamente ao departamento interno das organizações, mas também contam com o P\&D externo, que é capaz de gerar valor às organizações por meio do envolvimento de parcerias e acordos de cooperação.

Ressalte-se que, apesar de autores como Bonaccorsi e Piccaluga (1994), Segatto-Mendes (1996) e Porto (2000) indicarem que os motivos sociais também são considerados na busca de estabelecer parcerias com ICTs, os achados desta pesquisa indicaram ser essa, dentre todas as categorias, a de menor importância na opinião dos respondentes.

Esse fato pode ser comprovado, pois para nenhuma questão desta categoria, o percentual de "Concordo Totalmente" obteve um percentual de 
respostas de atingisse ao menos $30 \%$ das respostas. Por outro lado, foi possível verificar um índice maior de "Discordo Parcialmente" e "Discordo Totalmente" em relação às demais categorias, o que indica uma forte evidência de que as organizações ainda não têm como motivo principal estabelecer parcerias classificadas nesta categoria. Dessa maneira, esse achado merece um estudo aprofundado para entender as razões e as características desse fenômeno, uma vez que temas como responsabilidade social e ambiental são atuais e amplamente discutidos e difundidos na sociedade.

\section{CONSIDERAÇÕES FINAIS}

No presente estudo, o objetivo foi hierarquizar os principais fatores que levam as empresas a adotar parcerias com institutos de ciência e tecnologia (ICTs) e universidades. Dentre uma série de variáveis levantadas a partir de revisão bibliográfica, podem-se identificar sete como sendo as mais relevantes: fortalecimento da tecnologia da empresa, busca de novas fontes de criatividade, obtenção de expertise em tecnologias para o mercado, aquisição de novas tecnologias, acesso a mão de obra qualificada, capacitação de recursos humanos e desenvolvimento de novos produtos.

De modo geral, os resultados indicam que as empresas que adotam parcerias com ICTs e universidades buscam fortemente estabelecer tais relações visando a oportunidades e melhorias tecnológicas. No lado oposto, está a constatação de que motivações com vistas à contribuição social se mostram pouco relevantes.

Como limitações à pesquisa, destaque-se a amostra pouco representativa das empresas que mantêm parcerias com ICTs, o que não permite realizar generalizações. Ademais, em função do tamanho da amostra, as respostas foram todas analisadas de modo agregado, não possibilitando a realização de análises específicas para subgrupos, como exemplo, hierarquizar fatores motivacionais para determinados setores da economia.

Para pesquisas futuras, sugere-se o estudo com empresas de setores específicos para traçar o perfil específico de suas 
necessidades/motivações. Outro ponto que pode ser mais aprofundado diz respeito à categoria Contribuições Sociais, visto que as empresas assinalaram ser o item de menor importância em comparação às demais categorias analisadas. 


\section{REFERÊNCIAS}

Associação Nacional de Pesquisa e Desenvolvimento das Empresas Inovadoras - Anpei. (2015). Estatísticas. Recuperado em 14 de abril, 2016, de http:// http://anpei.org.br/estatisticas/

Bonaccorsi, A., \& Piccaluga, A. (1994). A theoretical framewok for the evoluation of university-industry relationships. R\&D Management, 24(3), 229-247.

Decreto $n^{\circ}$ 5.798, de 7 de junho de 2006. (2006). Regulamenta os incentivos fiscais às atividades de pesquisa tecnológica e desenvolvimento de inovação tecnológica, de que tratam os arts. 17 a 26 da Lei $n^{\circ} 11.196$, de 21 de novembro de 2005. Brasília, DF.

Coordenação de Aperfeiçoamento de Pessoal de Nível Superior - Capes. (2010). Plano Nacional da Pós-Graduação (vol. 1). Brasília: Capes. Recuperado em 24 de abril, 2016, de http://trienal.capes.gov.br/wp-content/uploads/2011/08/relatorio_geral_ dos_resultados_finais_da-avaliacao_2010.pdf

Coordenação de Aperfeiçoamento de Pessoal de Nível Superior - Capes. (2013). Resultados da avaliação da Capes revelam que pós-graduação teve crescimento de 23\% no triênio. Recuperado em 23 de abril, 2016, de http://www.capes.gov.br/36-noticias/6689-resultados-da-avaliacaoda-capes-revelam-que-pos-graduacao-teve-crescimento-de-23-notrienio.

Costa, E. F. (1998). A interação universidade/empresa e o papel do Estado: um caso de sucesso. In A. G. Plonski (Coord.), Interação universidadeempresa (vol. 1, pp. 262-281). Brasília: IBICT.

Costa, P. R.; Porto, G. S. \& Feldhaus, D. (2010). Gestão da cooperação empresa-universidade: o caso de uma multinacional brasileira. Revista de Administração Contemporânea, 14(1), 100-121.

Cruz, C. H. B. (1999). Universidade, empresa e a inovação tecnológica. In A. G. Plonski (Coord.), Interação universidade-empresa (vol. 1, pp. 226240). Brasília: IBICT.

Enkel, E.; Gassmann, O., \& Chesbrough, H. (2009). Open R\&D and open innovation: exploring the phenomenon. R\&D Management, 39(1), 311316.

Etzkowitz, H., \& Leydesdorff, L. (2000). The dinamics of innovation: from National Systems and "Mode 2" to a Triple Helix os university-industrygovernment relations. Research Policy, 20(2), 109-123. 
Etzkowitz, H. (2003). Innovation in innovation: the triple helix of universityindustry-government relations. Social Science Information, 42(3), 293337.

Figueiredo, P. C. N. (1993). O "Triângulo de Sábato" e as alternativas brasileiras de inovação tecnológica. Revista de Administração Pública $R A P, 27(3), 84-97$.

Freeman, C., \& Soete, L. (1997). The economics of industrial innovation. (3a ed.). MIT Press.

Gil, A. C. (1998). Como elaborar projetos de pesquisa. São Paulo: Atlas.

Hair Jr., J. F., Babin, B., Money, A. H., \& Samouel, P. (2007). Fundamentos de métodos de pesquisa em administração. Porto Alegre: Bookman.

Hitt, M. A., Ireland, R. D., \& Hoskisson, R. E. (2012). Administração estratégica: competitividade e globalização. $2^{a}$. ed. São Paulo: Pioneira Thomson Learning, 2008.

Jonash, R. S., \& Sommerlatte, T. (2011). O valor da inovação: como as empresas mais avançadas atingem alto desempenho e lucratividade. Rio de Janeiro: Campus, 2001.

Organisation for Economic Co-operation and Development - OECD. (2005). Manual de Oslo: diretrizes para coleta e interpretação de dados sobre inovação (3a ed.). Brasília: Finep.

Marconi, M. A., \& Lakatos, E. M. (1996). Fundamentos de metodologia científica. São Paulo: Atlas.

Marcovitch, J. (1999). A cooperação da universidade moderna com o setor empresarial. Revista de Administração da USP - Rausp, 34(4), 13-17.

Martins, G. A., \& Theóphilo, C. R. (2009). Metodologia da investigação científica para ciências sociais aplicadas (2a ed). São Paulo: Atlas.

Plonski, G. A. (1995). Cooperação empresa-universidade na Ibero-América: estágio atual e perspectivas. Revista de Administração, 30(2), 65-74.

Plonski, G. A. (1998). Cooperação empresa-universidade no Brasil: um balanço prospectivo. In A. G. Plonski (Coord.), Interação universidadeempresa (vol. 1, pp. 09-23). Brasília: IBICT.

Porto, G. S. (2000). A decisão empresarial de desenvolvimento tecnológico por meio da cooperação empresa-universidade. Tese de Doutorado, Faculdade de Economia, Administração e Contabilidade da Universidade de São Paulo: SP, Brasil. 
Reis, D. (1998). Em busca da inovação tecnológica: motivações e barreiras para a cooperação. Revista Educação \& Tecnologia, 2(3), 38-54.

Segatto-Mendes, A. P. (1996). Análise do processo de cooperação tecnológica universidade-empresa: um estudo exploratório. Dissertação de Mestrado, Faculdade de Economia, Administração e Contabilidade da Universidade de São Paulo: SP, Brasil.

Segatto-Mendes, A. P., \& Sbragia, R. (2002). O processo de cooperação universidade-empresa em universidades brasileiras. Revista de Administração da USP - Rausp, 37(4), 58-71.

Stal, E., Campanário, M. A., Andreassi, T., \& Sbragia, R. (Coords.). (2006). Inovação: como vencer esse desafio empresarial. São Paulo: Clio.

Tidd, J., Bessant, J., \& Pavitt, K. (2008). Gestão da inovação (3a ed.). Porto Alegre: Bookman.

Vergara, S. C. (2009). Projetos e relatórios de pesquisa em administração (10a ed.). São Paulo: Atlas. 